Research Paper

\title{
Carbapenem and cefoxitin resistance of Klebsiella pneumoniae strains associated with porin OmpK36 loss and DHA-1 $\beta$-lactamase production
}

\author{
Weifeng $\mathrm{Shi}^{1}$, Kun $\mathrm{Li}^{1}$, Yun $\mathrm{Ji}^{1}$, Qinbo Jiang ${ }^{1}$, Yuyue Wang ${ }^{1}$, Mei Shi ${ }^{1}$, Zuhuang $\mathrm{Mi}^{2}$ \\ ${ }^{1}$ Department of Clinical Laboratory, Third Affiliated Hospital of Suzhou University, \\ Changzhou, P.R. China. \\ ${ }^{2}$ Wuxi Clone Gen-Tech Institute, Wuxi, P.R. China.
}

Submitted: April 03, 2011; Approved: September 10, 2012.

\begin{abstract}
Clinical isolates of carbapenem-resistant Klebsiella pneumoniae (K. pneumoniae) strains are being increased worldwide. Five pan-resistant $K$. pneumoniae strains have been isolated from respiratory and ICU wards in a Chinese hospital, and reveal strong resistance to all $\beta$-lactams, fluoroquinolones and aminoglycosides. Totally $27 \beta$-lactamase genes and 2 membrane pore protein (porin) genes in 5 $K$. pneumoniae strains were screened by polymerase chain reaction (PCR). The results indicated that all of $5 \mathrm{~K}$. pneumoniae strains carried blaTEM-1 and blaDHA-1 genes, as well as base deletion and mutation of $O m p K 35$ or $O m p K 36$ genes. Compared with carbapenem-sensitive isolates by sodium dodecyl sulfate-polyacrylamide gel electrophoresis (SDS-PAGE), the resistant isolates markedly lacked the protein band of 34-40 $\mathrm{kDa}$, which might be the outer membrane proteins of OmpK36 according to the electrophoresis mobility. In addition, the conjugation test was confirmed that blaDHA-1 mediated by plasmids could be transferred between resistant and sensitive strains. When reserpine $(30 \mu \mathrm{g} / \mathrm{mL})$ and carbonyl cyanide $m$-chlorophenylhydrazone (CCCP) $(50 \mu \mathrm{g} / \mathrm{mL})$ were added in imipenem and meropenem, the MICs had no change against $K$. pneumoniae strains. These results suggest that both DHA- $1 \beta$-lactamase and loss or deficiency of porin OmpK36 may be the main reason for the cefoxitin and carbapenem resistance in $K$. pneumoniae strains in our hospital.
\end{abstract}

Key words: Klebsiella pneumoniae, AmpC $\beta$-Lactamase, Porin, molecular biology.

\section{Introduction}

K. pneumoniae is one of the most common pathogens in clinical infections, such as pneumonia, urinary tract infections, sepsis, wound infections, meningitis and other diseases. Multidrug-resistant K. pneumoniae strains are becoming a severe problem worldwide, and it usually carries one or more extended-spectrum $\beta$-lactamases (ESBLs) that confers the resistance to expanded-spectrum cephalosporins (Lee et al., 2007; Huang and Hsueh, 2008). In recent years, $K$. pneumoniae strains have been reported to be resistant to most $\beta$-lactamas through mutation genes encoded in chromosome, acquisition of genes from mobile plasmids and integrons (Maltezou et al., 2009; Munoz-Price and Quinn, 2009).
Carbapenem antibiotics are very effective in the treatment of severe bacterial infections caused by ESBL- and AmpC enzymes-producing K. pneumoniae strains so that they have been widely used in clinics. Due to carbapenemases, metallo- $\beta$-lactamases and porin loss, carbapenem-resistant $K$. pneumoniae strains are increasing (Landman et al., 2009; Pournaras et al., 2010). Up to now, it has been reported that the outer membrane proteins of $K$. pneumoniae strains contain three known porins including OmpK35, OmpK36, and OmpK37 (Hernandez-Alles et al., 1999; Kaczmarek et al., 2006). Furthermore, porins OmpK35 and OmpK36 play critical roles in the penetration of antibiotics into the cells, and the loss of OmpK35 or OmpK36 can resist or reduce susceptibility to cephalosporins and carbapenems, particularly in strains containing

Send correspondence to W. Shi. Department of Clinical Laboratory, Third Affiliated Hospital of Suzhou University, No.185 Juqian Road, 213003 Changzhou, P.R. China. E-mail: swf67113@163.com. 
Ambler group A, B, C, or D $\beta$-lactamase (Doumith et al., 2009; Goldfarb et al., 2009; Kontopoulou et al., 2010).

In 2010, we isolated $5 \mathrm{~K}$. pneumoniae strains resistant to almost all antibiotics from clinical specimens. The minimal inhibitory concentrations (MICs) of piperacillin, piperacillin/tazobactam, amoxicillin/clavulanic acid, cefoperazone/sulbactam, cefoxitin, cefotaxime and aztreonam against $5 \mathrm{~K}$. pneumoniae strains were larger than $128 \mu \mathrm{g} / \mathrm{mL}$, and the MICs of imipenem and meropenem against $5 \mathrm{~K}$. pneumoniae strains were larger than $32 \mu \mathrm{g} / \mathrm{mL}$. In addition, these $K$. pneumoniae strains also revealed the resistance to ciprofloxacin, levofloxacin, gentamicin and amikacin (MIC $\geq 64 \mu \mathrm{g} / \mathrm{mL}$ ). The objective of this study was to investigate the cause of high-level carbapenem resistance in K. pneumoniae strains. Except for blaTEM-1 and blaDHA-1 genes, carbapenem-resistant genes were not observed in $5 \mathrm{~K}$. pneumoniae strains; however, the base deletion or mutation of $O m p K 35$ and OmpK36 genes could lead to the alterations of amino acid sequences, protein configuration and pore size of porins, thus impeding the access of antimicrobials. Therefore, high-level resistance to cefoxitin and carbapenem in $5 \mathrm{~K}$. pneumoniae clinical isolates is due to the combinatorial action from the production of blaDHA-1 beta-lactamase and the insertional inactivation or loss of porin OmpK36.

\section{Methods}

\section{Strains and antimicrobial susceptibility testing}

In 2010,5 carbapenem-resistant $K$. pneumoniae (Kp01, Kp02, Kp03, Kp04 and Kp05) strains were isolated from sputum, urine and deep venous catheter specimens in a Chinese hospital. Among 5 patients, 1 case was from respiratory ward and 4 cases were from ICU ward. The MICs of piperacillin, peracillin/sulbactam, amoxicillin/clavulanic acid, cefoperazone/sulbactam, cefoxitin, cefotaxime, cefepime, aztreonam, imipenem, meropenem, ciprofloxacin, levofloxacin, gentamicin and amikacin were performed by E-test (Oxiod), and E. coli ATCC25922 was used as the control.

\section{Extraction of $\beta$-lactamase and three-dimensional test}

Briefly, a colony was inoculated into $5 \mathrm{~mL}$ of tryptic soy broth overnight and the culture was grown at $35^{\circ} \mathrm{C}$ for $4 \mathrm{~h}$. The cells were concentrated by centrifugation, and crude enzyme extract was prepared by repeated freezethawing cycle for five times. The surface of a MuellerHinton agar plate was inoculated with E.coli strains as described by the standard disk diffusion method. A $30 \mu \mathrm{g}$ cefoxitin disk (Oxoid) was placed on the inoculated agar. With a sterile scalpel blade, 4 slit beginning $5 \mathrm{~mm}$ from the edge of the disk was cut in the agar in outward radial direction. By using a pipette, $40 \mu \mathrm{L}$ of crude enzyme extract was dispensed into each slit, beginning near the disk and mov- ing outward. Slit overfill was avoided. The inoculated media were incubated overnight at $35^{\circ} \mathrm{C}$. Enhanced growth of the surface organism at the point where the slit intersected the zone of inhibition was considered a positive three-dimensional testing result and was interpreted as the evidence in the presence of AmpC beta-lactamase or ESBL. K. pneumoniae ATCC700603 and Enterobacter cloacae (E. cloacae) $029 \mathrm{M}$ were used as the control strains.

\section{Transconjugation experiments}

In order to determine if the resistance was transferable, transconjugation experiments were performed. Five isolates were used as the donors and EC600 (Rif ${ }^{\mathrm{r}}$ ) was used as the recipient in transconjugation experiments. The organisms were inoculated into $5 \mathrm{~mL}$ of Luria-Bertani (LB) broth (Difco) and incubated at $35^{\circ} \mathrm{C}$ for $20 \mathrm{~h}$ with shaking. Two organisms were mixed together at a proportion of $1: 2$, and then incubated overnight at $35^{\circ} \mathrm{C}$ with shaking. After centrifugation for $5 \mathrm{~min}$ at $4,000 \mathrm{~g}$, the precipitate was mixed with $1 \mathrm{~mL}$ of distilled water and inoculated onto MacConkey agar plates containing $600 \mu \mathrm{g} / \mathrm{mL}$ rifampin and $0.25 \mu \mathrm{g} / \mathrm{mL}$ cefotaxime. Transparent colonies were selected from the agar plates and inoculated into MacConkey agar again for activation. The drug-resistant profile and plasmid electrophoresis were further analyzed.

\section{DNA extraction}

Strains were grown overnight on MacConkey agar plates at $37{ }^{\circ} \mathrm{C}$, and growth from approximately onequarter of a plate was resuspended in $180 \mu \mathrm{L}$ of distilled water. A total of $200 \mu \mathrm{L}$ of buffer solution $(0.01 \mathrm{mM}$ Tris-HCl, pH 7.8; 0.005 M EDTA; 0.5\% sodium dodecyl sulfate) and $20 \mu \mathrm{L}$ of proteinase $\mathrm{K}(1 \mathrm{mg} / \mathrm{mL})$ were added. The mixture was incubated at $55{ }^{\circ} \mathrm{C}$ for $2 \mathrm{~h}$, and then $400 \mu \mathrm{L}$ of phenol-chloroform solution was added, mixed with gentle agitation, and centrifuged at 12,000 $\mathrm{g}$ for $5 \mathrm{~min}$. The supernatant was collected and DNA was precipitated after the addition of 0.5 volume of $7.5 \mathrm{M}$ ammonium acetate and 2 volumes of ethanol. DNA was washed with $70 \%$ ethanol, dried, and resuspended with $100 \mu \mathrm{L}$ of Tris-EDTA buffer.

\section{Analysis of $\beta$-lactamase and porin genes}

The oligonucleotide primers were designed on the basis of the nucleotide sequence in GenBank (Table 1). The $27 \beta$-lactamase and 2 porin genes were screened by PCR. The primer pairs were shown in Table 1 . The assay was carried out in $20 \mu \mathrm{L}$ of reaction mixture containing $0.5 \mu \mathrm{M}$ each primer, $10 \mathrm{mM} \mathrm{KCl,} 2 \mathrm{mM} \mathrm{MgCl} 2,8 \mathrm{mM}(\mathrm{NH} 4)_{2} \mathrm{SO}_{4}$, $10 \mathrm{mM}$ Tris- $\mathrm{HCl}$ (pH 9.0), $200 \mu \mathrm{M}$ dNTP and $1 \mathrm{U}$ Taq DNA polymerase. All amplification reactions were performed with an initial denaturation at $93{ }^{\circ} \mathrm{C}$ for $3 \mathrm{~min}$ followed by 35 cycles of denaturation at $93{ }^{\circ} \mathrm{C}$ for $1 \mathrm{~min}$, an- 
Table 1 - Primers used in this study.

\begin{tabular}{|c|c|c|c|}
\hline Target genes & Primer sequence $\left(3^{\prime} \rightarrow 5^{\prime}\right)$ & Size (bp) & $\begin{array}{l}\text { GenBank accession } \\
\text { no. of reference }\end{array}$ \\
\hline \multicolumn{4}{|c|}{ Class A $\beta$-lactamases } \\
\hline \multirow[t]{2}{*}{ TEM } & P1: AGGAAGAGTATGATTCAACA & & \\
\hline & P2: CTCGTCGTTTGGTATGGC & $535 \mathrm{bp}$ & X54604 \\
\hline \multirow[t]{2}{*}{ SHV } & P1: TGCGCAAGCTGCTGACCAGC & & \\
\hline & P2:TTAGCGTTGCCAGTGCTCGA & $305 \mathrm{bp}$ & AY326946 \\
\hline \multirow[t]{2}{*}{ CTX-M-1 group } & P1: ATGGTTAAAAAATCACTGCGC & & \\
\hline & P2: TCCCGACGGCTTTCCGCCTT & $833 \mathrm{bp}$ & GU125714 \\
\hline \multirow[t]{2}{*}{ CTX-M-2 group } & P1: ATGATGACTCAGAGCATTCG & & \\
\hline & P2: TCCCGACGGCTTTCCGCCTT & $833 \mathrm{bp}$ & AY750915 \\
\hline \multirow[t]{2}{*}{ CTX-M-8 group } & P1: ATGATGAGACATCGCGTTAAGCGG & & \\
\hline & P2: TTAATAACCGTCGGTGACGATTTTCGCG & $876 \mathrm{bp}$ & AF189721 \\
\hline \multirow[t]{2}{*}{ CTX-M-9 group } & P1: CGGCCTGTATTTCGCTGTTG & & \\
\hline & P2: TCCCGACGGCTTTCCGCCTT & $793 \mathrm{bp}$ & AB205197 \\
\hline \multirow[t]{2}{*}{ CTX-M-25 group } & P1: ATGATGAGAAAAAGCGTAAGGCGGGCG & & \\
\hline & P2: TCCCGACGGCTTTCCGCCTT & 876 bp & AY157676 \\
\hline \multirow[t]{2}{*}{ PER } & P1: AGTCAGCGGCTTAGATA & & \\
\hline & P2: CGTATGAAAAGGACAATC & $978 \mathrm{bp}$ & AJ621265 \\
\hline \multirow[t]{2}{*}{ GES } & P1: ATGCGCTTCATTCACGCAC & & \\
\hline & P2: CTATTTGTCCGTGCTCAGG & $846 \mathrm{bp}$ & AY219651 \\
\hline \multirow[t]{2}{*}{ VEB } & P1: GCGGTAATTTAACCAGA & & \\
\hline & P2: GCCTATGAGCCAGTGTT & $961 \mathrm{bp}$ & AY536743 \\
\hline \multirow[t]{2}{*}{ CARB } & P1: AAAGCAGATCTTGTGACCTATTC & & \\
\hline & P2: TCAGCGCGACTGTGATGTATAAAC & $588 \mathrm{bp}$ & S46063 \\
\hline \multirow[t]{2}{*}{$\mathrm{KPC}$} & P1: ATGTCACTGTATCGCCGTCTA & & \\
\hline & P2: TTACTGCCCGTTGACGCCCAA & $882 \mathrm{bp}$ & GU086225 \\
\hline \multirow[t]{2}{*}{ LAP } & P1: ATGAAAAAGATCCGCCTTATTATAA & & \\
\hline & P2: TTACCAGTTCTTAATTACTGAATC & $858 \mathrm{bp}$ & EF026092 \\
\hline \multicolumn{4}{|c|}{ Class B $\beta$-lactamases } \\
\hline \multirow[t]{2}{*}{ IMP } & P1: CGGCCGCAGGAGAGGCTTT & & \\
\hline & P2: AACCAGTTTTGCCTTACCAT & $587 \mathrm{bp}$ & AJ223604 \\
\hline \multirow[t]{2}{*}{ VIM } & P1: ATTCCGGTCGGAGAGGTCCG & & \\
\hline & P2: GAGCAAGTCTAGACCGCCCG & $633 \mathrm{bp}$ & AY509609 \\
\hline \multirow[t]{2}{*}{ SPM } & P1: CTGCTTGGATTCATGGGCGCG & $784 \mathrm{bp}$ & AY341249 \\
\hline & P2: CCTTTTCCGCGACCTTGCTCG & & \\
\hline \multirow[t]{2}{*}{ NDM } & P1: TCAGCGCAGCTTGTCGGCCA & $813 \mathrm{bp}$ & HQ738352 \\
\hline & P2: ATGGAATTGCCCAATATTATGCA & & \\
\hline \multicolumn{4}{|c|}{ Class C $\beta$-lactamases } \\
\hline \multirow[t]{2}{*}{ LEN } & P1: ATGCGTTATATTCGCCTGTG & $591 \mathrm{bp}$ & AM850914 \\
\hline & P2: GGCGCTCAGATGCTGCGC & & \\
\hline \multirow[t]{2}{*}{ OKP } & P1: AAGCGCTTCCCGGCGACGTG & $362 \mathrm{bp}$ & AM051141 \\
\hline & P2: TTAGCGTTGCCAGTGCTCGA & & \\
\hline \multirow[t]{2}{*}{ DHA } & P1: AACTTTCACAGGTGTGCTGGGT & $405 \mathrm{bp}$ & AY585202 \\
\hline & P2: CCGTACGCATACTGGCTTTGC & & \\
\hline \multirow[t]{2}{*}{$\mathrm{ACT}$} & P1: TCGGTAAAGCCGATGTTGCGG & $303 \mathrm{bp}$ & EF508682 \\
\hline & P2: CTTCCACTGCGGCTGCCAGTT & & \\
\hline
\end{tabular}


Table 1 (cont.)

\begin{tabular}{|c|c|c|c|}
\hline Target genes & Primer sequence $\left(3^{\prime} \rightarrow 5^{\prime}\right)$ & Size (bp) & $\begin{array}{l}\text { GenBank accession } \\
\text { no. of reference }\end{array}$ \\
\hline \multirow[t]{2}{*}{ MOX } & P1: GCTGCTCAAGGAGCACAGGAT & $520 \mathrm{bp}$ & EU515248 \\
\hline & P2: CACATTGACATAGGTGTGGTG & & \\
\hline \multirow[t]{2}{*}{$\mathrm{ACC}$} & P1: ACAGCCTCAGCAGCCGGTTA & $345 \mathrm{bp}$ & AJ133121 \\
\hline & P2: TTCGCCGCAATCATCCCTAG & & \\
\hline \multirow[t]{2}{*}{ FOX } & P1: AACATGGGGTATCAGGGAGAT & $190 \mathrm{bp}$ & AY034848 \\
\hline & P2: CAAAGCGCGTAACCGGATTGG & & \\
\hline \multicolumn{4}{|c|}{ Class D $\beta$-lactamases } \\
\hline \multirow[t]{2}{*}{ OXA-1 group } & P1: CTGTTGTTTGGGTTTCGCAAG & $440 \mathrm{bp}$ & GQ438248 \\
\hline & P2: CTTGGCTTTTATGCTTGATG & & \\
\hline \multirow[t]{2}{*}{ OXA-2 group } & P1: CAGGCGCTGTTCGTGATGAGTT & $233 \mathrm{bp}$ & FJ855130 \\
\hline & P2: GCCTTCTATCCAGTAATCGCC & & \\
\hline \multirow[t]{2}{*}{ OXA-10 group } & P1: GTCTTTCAAGTACGGCATTA & 822 bp & AY509609 \\
\hline & P2: GATTTTCTTAGCGGCAACTTA & & \\
\hline \multicolumn{4}{|l|}{ Porin } \\
\hline \multirow[t]{2}{*}{ ompK35 } & P1: ATGATGAAGCGCAATATTCTGGCAGTGG & $684 \mathrm{bp}$ & GU945384 \\
\hline & P2: TCGGCTTTGTCGCCATTGCCGTCA & & \\
\hline \multirow[t]{2}{*}{ ompK36 } & P1: ATGAAAGTTAAAGTACTGTCCCTC & 1076 bp & HM000057 \\
\hline & P2: GCCGGTATCTCTACCGACGAC & & \\
\hline
\end{tabular}

nealing at $55^{\circ} \mathrm{C}$ for $1 \mathrm{~min}$ and extension at $72{ }^{\circ} \mathrm{C}$ for $1 \mathrm{~min}$. The final extension was performed at $72{ }^{\circ} \mathrm{C}$ for $7 \mathrm{~min}$. Aliquot $(20 \mu \mathrm{L})$ of each sample was subjected to electrophoresis by $2 \%$ agarose gels. The amplicons were purified with PCR Cleanup kits (Roche Molecular Biochemicals) and sequenced on an ABI PRISM 377 analyzer (Applied Biosystems).

\section{Outer membrane protein analysis}

K. pneumoniae was inoculated overnight in $5 \mathrm{~mL}$ of LB medium at $35^{\circ} \mathrm{C}$ with shaking, the culture was added in $200 \mathrm{~mL}$ of LB liquid medium at $35^{\circ} \mathrm{C}$ with shaking for $5 \mathrm{~h}$. After centrifugation $\left(4^{\circ} \mathrm{C}\right.$ ) for $5 \mathrm{~min}$ at $4,000 \mathrm{~g}$, the supernatant was discarded. The precipitate was washed three times with $50 \mathrm{mM}$ ( $\mathrm{pH}$ 7.0) phosphate buffer solution (PBS), and suspended in $10 \mathrm{mM}$ Tris- $\mathrm{HCl}$ ( $\mathrm{pH} 7.4)$. The ultrasonic fragmentation of bacteria was performed in ice bath conditions. In order to remove unbroken bacteria, centrifugation was performed at $4,000 \mathrm{~g}$ for $30 \mathrm{~min}$, and then the supernatant was centrifuged at 25,000 $\mathrm{g}$ for another $30 \mathrm{~min}$. The precipitation was resuspended with buffer, and phenylmethylsulfonyl was added. The outer membrane protein was denatured at $100{ }^{\circ} \mathrm{C}$ for 5 min before electrophoresis and then separated by SDS-PAGE with Mini-sub cell horizontal electrophoresis tank (Biorad Co.). The gel concentration was $12.0 \%$, and stained with Coomassie brilliant blue R250 for $30 \mathrm{~min}$.

\section{Inhibitory effects of reserpine and CCCP against} efflux

Susceptibility test was carried out using agar dilution method. MIC changes were observed in the absence or presence of reserpine (J \& K Chemical) and CCCP (Sigma) at concentrations of $30 \mu \mathrm{g} / \mathrm{mL}$ and $50 \mu \mathrm{g} / \mathrm{mL}$, respectively. An inoculum of each isolate at the amount of $5 \times 10^{4}$ $\mathrm{cfu} / \mathrm{mL}$ was inoculated onto $\mathrm{MH}$ medium containing serial dilutions of imipenem and meropenem. A phenotype for positive efflux was detectable after at least 4-fold dilutions of MIC for imipenem or meropenem in the absence or presence of reserpine and CCCP.

\section{Results}

\section{Antimicrobial susceptibility test}

In vitro tests showed that the MICs of piperacillin, piperacillin/tazobactam, amoxicillin/clavulanic acid, cefoperazone/sulbactam, cefoxitin, cefotaxime and aztreonam against $5 \mathrm{~K}$. pneumoniae strains were larger than $128 \mu \mathrm{g} / \mathrm{mL}$, and the MICs of imipenem or meropenem against $5 \mathrm{~K}$. pneumoniae strains were larger than $32 \mu \mathrm{g} / \mathrm{mL}$. In addition, $5 \mathrm{~K}$. pneumoniae strains also revealed strong resistance to ciprofloxacin, levofloxacin, gentamicin and amikacin (Table 2). 
Table 2 - MICs of $\beta$-lactams, fluoroquinolones and aminoglycosides against $K$. pneumoniae strains.

\begin{tabular}{lcccccc}
\hline \multirow{2}{*}{$\begin{array}{l}\text { Antimicrobial } \\
\text { agents }\end{array}$} & \multicolumn{7}{c}{ MIC $(\mu \mathrm{g} / \mathrm{mL})$} \\
\cline { 2 - 7 } & \multicolumn{7}{c}{ Kp01 } & $K p 02$ & $K p 03$ & $K p 04$ & $K p 05$ & $E C 600$ \\
\hline Piperacillin & $>256$ & $>256$ & $>256$ & $>256$ & $>256$ & 1 \\
Piperacillin/sul & $>256$ & $>256$ & $>256$ & $>256$ & $>256$ & 1 \\
bactam & & & & & & \\
Amoxicillin/cla & $>256$ & $>256$ & $>256$ & $>256$ & $>256$ & 0.5 \\
vulanic acid & & & & & & \\
Cefoxitin & $>256$ & $>256$ & $>256$ & $>256$ & $>256$ & 4 \\
Cefotaxime & $>256$ & $>256$ & $>256$ & $>256$ & $>256$ & 0.25 \\
Cefoperazone/s & $>256$ & $>256$ & $>256$ & $>256$ & $>256$ & $\leq 0.125$ \\
ulbactam & & & & & & \\
Cefepime & 128 & 128 & $>256$ & $>256$ & 128 & $\leq 0.125$ \\
Aztreonam & $>256$ & $>256$ & $>256$ & $>256$ & $>256$ & $\leq 0.125$ \\
Imipenem & $>32$ & $>32$ & $>32$ & $>32$ & $>32$ & $\leq 0.125$ \\
Meropenem & $>32$ & $>32$ & $>32$ & 32 & 32 & $\leq 0.125$ \\
Ciprofloxacin & $>128$ & $>128$ & $>128$ & 64 & 128 & $\leq 0.125$ \\
Levofloxacin & $>128$ & $>128$ & $>128$ & 64 & 64 & $\leq 0.125$ \\
Gentamicin & $>128$ & $>128$ & $>128$ & $>128$ & 128 & $\leq 0.125$ \\
Amikacin & $>128$ & $>128$ & $>128$ & 128 & 128 & $\leq 0.125$ \\
\hline
\end{tabular}

Kp01, Kp02, Kp03, Kp04 and Kp05: carbapenem-resistant $K$. pneumoniae strains.

\section{Three dimension test}

All 5 isolates exhibited positive three-dimensional test results, and their extracts promoted the growth of one surface organism of E.coli ATCC25922 on MH agar. E. cloacae $029 \mathrm{M}$ could produce AmpC enzyme to exhibit an interference with the growth of ATCC25922. ATCC700603 was used as the negative control (Figure 1).

\section{Sequence analysis of $\beta$-lactamase, OmpK35 and OmpK36 genes}

The PCR and sequence analysis showed that $K p 01$, $K p 02, K p 03, K p 04$ and $K p 05$ contained TEM and DHA $\beta$-lactamase genes. Compared with blaTEM-1 (Accession No. FJ668746) and blaDHA-1 (Accession No. HM193083) in GenBank, these strains shared 100\% identity. Similarly, OmpK35 and OmpK36 genes in 5 multidrug-resistant $K$. pneumoniae strains were detected by PCR amplification and sequence analysis. Among 5 K. pneumoniae strains, the base deletions of $O m p K 35$ and $O m p K 36$ genes were observed in $K p 01$ and $K p 03$ strains, and the base deletion of $O m p K 35$ gene was also observed in Kp02 and Kp05. In $O m p K 36$ gene, insertion and deletion as well as the mutations of short DNA fragment (1-5 bp) could result in the alteration of open reading frame and early termination of translation. In addition, mutations of $\mathrm{OmpK} 35$ gene occurred in Kp04 (Table 3). Compared with GU945384 in GenBank, OmpK35 gene mutations of $\mathrm{G} \rightarrow \mathrm{C}$ at base 465

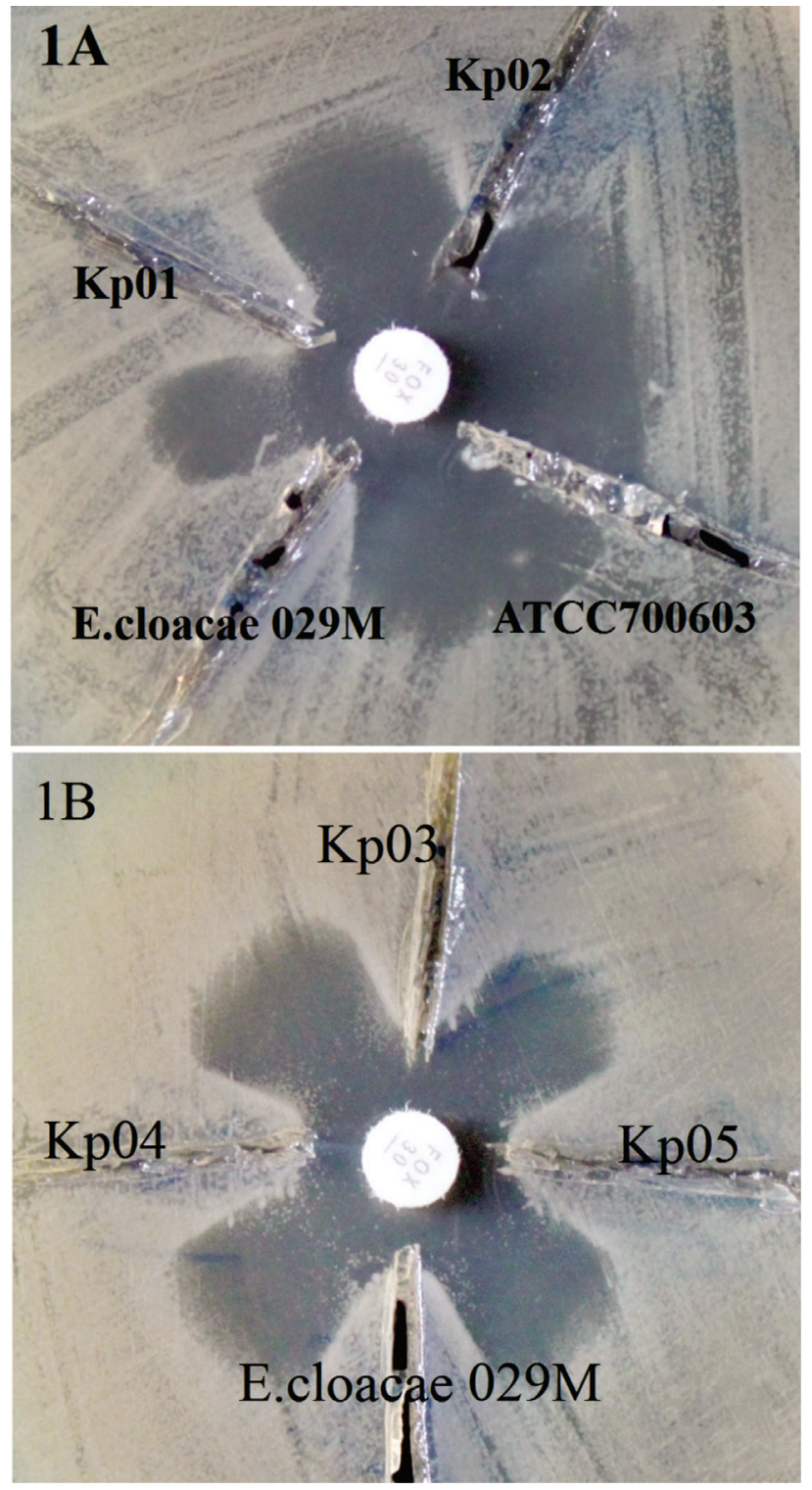

Figure 1 - Three-dimensional test for five strain isolates. (1A) Enhanced growth of E.coli ATCC25922 was observed near agar slits containing enzyme extracts of $K p 01, K p 02$ and E. cloacae 029 M. Except for ATCC700603, all of them were AmpC producers. (1B) Kp03, Kp04, Kp 05 and E. cloacae $029 \mathrm{M}$ could interfere with the growth of $E$. coli ATCC25922.

and $\mathrm{T} \rightarrow \mathrm{C}$ at base 466 in $K p 04$ could also result in the substitution from Gln to His at position 155 and substitution from Tyr to His at position 156. A new subtype has been registered in GenBank (Accession No. HQ259027).

\section{Transconjugation test of $K$. pneumoniae}

EC600 was used as the recipient in the conjugation studies. In addition, blaDHA-1 resistant genes from $K p 01$, $K p 02, K p 03$ and $K p 05$ were transferred into the recipient EC600 and confirmed by PCR. EC600 resulted in drug resistance from $K p 01, K p 02, K p 03$ and $K p 05$ to a certain degree, and the MICs of piperacillin, piperacillin/sulbactam, 
amoxicillin/clavulanic acid and cefotaxime exhibited 2-16 fold increase (Table 4).

\section{SDS-PAGE of outer membrane protein}

The outer membrane proteins of 4 strains were detected by SDS-PAGE. Compared with the sensitive strains, the lack of outer membrane proteins in 3 carbepenem-resistant $K$. pneumoniae strains $(K p 01, K p 02$ and $K p 04)$ were detected by SDS-PAGE, and molecular weights of these outer membrane proteins were $34-40 \mathrm{kDa}$, which suggested that only porin loss of OmpK36 in $K p 01, K p 02$ and $K p 04$ strains when compared with $K$. pneumoniae ATCC700603 and sensitive strains. In contrast, the porin of OmpK35 and OmpK36 was remained in $\mathrm{Kp} 03$ (Figure 2).

\section{Inhibitory effects of reserpine and CССP on the efflux of $K$. pneumoniae}

All strains with a concentration of $5 \times 10^{4} \mathrm{cfu} / \mathrm{mL}$ can grow in the presence of $256 \mu \mathrm{g} / \mathrm{mL}$ reserpine and $128 \mu \mathrm{g} / \mathrm{mL}$ CCCP. When reserpine $(30 \mu \mathrm{g} / \mathrm{mL})$ and CCCP $(50 \mu \mathrm{g} / \mathrm{mL})$ were added in imipenem and meropenem, no change of MICs was observed in the presence of reserpine and CCCP.

Table 3 - Expression of two porins in five K. pneumoniae strains.

\begin{tabular}{ccccc}
\hline Strains & blaTEM-1 & blaDHA-1 & OmpK36 gene & OmpK35 gene \\
\hline Kp01 & + & + & Base deletion & Base deletion \\
Kp02 & + & + & Insertion & Base deletion \\
Kp03 & + & + & Base deletion & Base deletion \\
Kp04 & + & + & Insertion & Mutation \\
Kp05 & + & + & Insertion & Base deletion \\
\hline
\end{tabular}

Table 4 - The antimicrobial susceptibility of transconjugants.

\begin{tabular}{lcccc}
\hline \multirow{2}{*}{ Antimicrobial agents } & \multicolumn{4}{c}{ MIC $(\mu \mathrm{g} / \mathrm{mL})$} \\
\cline { 2 - 5 } & $\operatorname{Tr} 01$ & $\operatorname{Tr} 02$ & $\operatorname{Tr} 03$ & $\operatorname{Tr} 05$ \\
\hline Piperacillin & 8 & 16 & 4 & 8 \\
Piperacillin/sulbactam & 4 & 8 & 8 & 4 \\
Amoxicillin/clavulanic & 4 & 8 & 4 & 4 \\
acid & & & & \\
Cefotaxime & 0.5 & 1 & 0.5 & 1 \\
Cefoperazone/sulbactam & 0.25 & 0.125 & 0.125 & 0.25 \\
Aztreonam & 0.25 & 0.25 & 0.25 & 0.5 \\
Cefepime & $\leq 0.125$ & $\leq 0.125$ & $\leq 0.125$ & $\leq 0.125$ \\
Imipenem & $\leq 0.125$ & $\leq 0.125$ & $\leq 0.125$ & $\leq 0.125$ \\
Meropenem & $\leq 0.125$ & $\leq 0.125$ & $\leq 0.125$ & $\leq 0.125$ \\
Ciprofloxacin & $\leq 0.125$ & $\leq 0.125$ & $\leq 0.125$ & $\leq 0.125$ \\
Amikacin & 0.25 & $\leq 0.125$ & 0.25 & 0.25 \\
\hline
\end{tabular}

Transconjugants: $\operatorname{Tr}$.

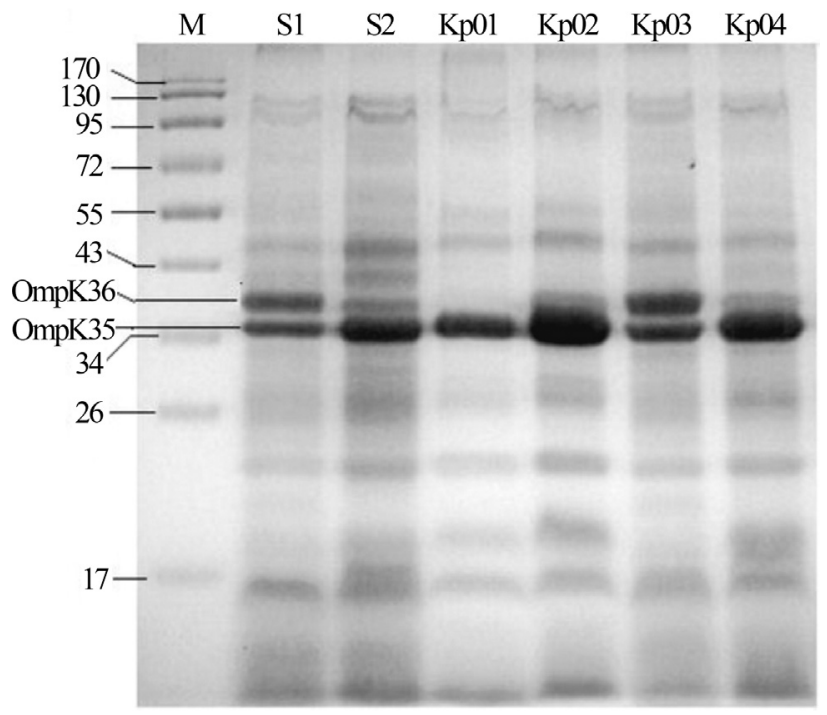

Figure 2 - SDS-PAGE of outer membrane proteins. M: Marker; S1: ATCC700603; S2: sensitive strain.

\section{Discussion}

In the present study, we screened $27 \beta$-lactamase genes including Ambler class A, B, C and D by using PCR technique. The metallo- $\beta$-lactamases, OXA-type and KPC-type $\beta$-lactamases were not detected by PCR in $5 \mathrm{~K}$. pneumoniae strains. However, all of 5 strains carried blaTEM-1 and blaDHA-1 $\beta$-lactamase genes. DHA-1, a plasmid-mediated AmpC type $\beta$-lactamase belonging to Ambler class $\mathrm{C}$, can confer the resistance to oxyiminocephalosporins (cefotaxime and ceftazidime) and cephamycins (cefoxitin and moxalactam), and transfer of the resistance has been confirmed by transconjugation (Lee, 2007; Ding et al., 2008; Yamada et al., 2009). In the present study, blaDHA-1 resistant genes from Kp01, Kp02, Kp 03 and $K p 05$ may be transferred into the recipient EC600, leading to 2-16 fold MIC increase of piperacillin, piperacillin/sulbactam, amoxicillin/clavulanic acid and cefotaxime. These findings indicate that blaDHA-1 $\beta$-lactamase gene can spread rapidly between the same and different bacteria.

The base deletion of $O m p K 35$ and $O m p K 36$ genes in $K p 01$ and $K p 03$ was simultaneously observed. Similarly, the base deletion of $O m p \mathrm{~K} 35$ also existed in $K p 02$ and $K p 05$. In addition, there were still genetic insertion of $O m p \mathrm{~K} 36$ in $\mathrm{Kp} 02$, Kp04 and Kp05. SDS-PAGE analysis of the OMPs revealed the only loss of $O m p \mathrm{~K} 36$ in $K p 01, K p 02$ and $K p 04$ strains when compared with $K$. pneumoniae ATCC700603 and a sensitive strains. However, the loss of porin was not observed in $K p 03$, which suggested that mutations or base deletions of porin-coding genes can lead to the alterations of open reading frame, amino acid sequences and protein configuration. Thus, the pore size of porin OmpK35 or OmpK36 can be affected and the accessibility 
of drugs can be impeded. Moreover, the porin OmpK36 plays an important role in the resistance or reduced susceptibility to carbapenems in $K$. pneumoniae strains (Hernandez-Alles, 1999; Wang et al., 2009). In this study, high-level carbapenem resistance in $5 \mathrm{~K}$. pneumoniae strains was associated with the deletion or mutation of porin genes. The lack or deficiency of outer membrane protein can result in the change of permeability and reduction of cell accessibility for antibiotics or other drugs, which plays an important role in the main channels (MartinezMartinez, 2008; Endimiani et al., 2009; Jiang et al., 2009; Landman, 2009). Therefore, blaDHA-1 $\beta$-lactamases combined with the absence of outer membrane proteins may confer to the carbapenems and cefoxitin resistance in $K$. pneumoniae strains (Su et al., 2008; Jiang et al., 2010).

Efflux systems that contribute to antibiotic resistance have been described for a number of clinically important bacteria (Guglierame et al., 2006; Coyne et al., 2010; Husain and Nikaido, 2010). The overexpression of multidrug efflux pumps can lead to low-level multi-drug resistance (Guglierame, 2006; Piddock, 2006). It has been reported that reserpine and CCCP were used as the pumps inhibitors (Shi et al., 2005). Reserpine is a well-established inhibitor of efflux pumps among Gram-positive microorganisms and non-fermenting Gram-negative microorganisms. CCCP can destroy the proton gradient of bacterial transcytoplasm membrane, causing transport proteins to lose energy supply and eventually leading to the increasing accumulation of drug concentration (Zhang et al., 2010). In this study, when reserpine and CCCP were added, MIC changes of imipenem and meropenem were not observed. The results indicated that the resistance of $K$. pneumoniae strains to carbapenems seems to be irrelevant to efflux.

Taken all together, the expression of porin OmpK36 coupled with blaDHA-1 $\beta$-lactamase genes plays an important role in conferring resistance of $K$. pneumoniae strains to carbapenems and cefoxitin in our hospital. Our findings highlight the urgent need to develop the strategies for the prevention and control of infections. Limited application of antimicrobials, especially for fluoroquinolones and cephalosporins, may be the effective strategies.

\section{Acknowledgments}

We really thank J Zhang and YH. Feng for their help of electrophoresis analysis.

\section{References}

Coyne S, Rosenfeld N, Lambert T, Courvalin Pand Perichon B (2010) Overexpression of resistance-nodulation-cell division pump AdeFGH confers multidrug resistance in Acinetobacter baumannii. Antimicrob Agents Chemother. 54:4389-4393.

Ding H, Yang Y, Lu Q, Wang Y, Chen Y, Deng L, Wang A, Deng Q, Zhang Hand Wang C (2008) The prevalence of plasmid-mediated AmpC $\beta$-lactamases among clinical isolates of Escherichia coli and Klebsiella pneumoniae from five children's hospitals in China. European journal of clinical microbiology \& infectious diseases 27:915-921.

Doumith M, Ellington MJ, Livermore DMand Woodford N (2009) Molecular mechanisms disrupting porin expression in ertapenem-resistant Klebsiella and Enterobacter spp. clinical isolates from the UK. J Antimicrob Chemother 63:659667.

Endimiani A, DePasquale JM, Forero S, Perez F, Hujer AM, Roberts-Pollack D, Fiorella PD, Pickens N, Kitchel Band Casiano-Colón AE (2009) Emergence of blaKPC-containing Klebsiella pneumoniae in a long-term acute care hospital: a new challenge to our healthcare system. Journal of Antimicrobial Chemotherapy 64:1102.

Goldfarb D, Harvey SB, Jessamine K, Jessamine P, Toye Band Desjardins M (2009) Detection of plasmid-mediated KPCproducing Klebsiella pneumoniae in Ottawa, Canada: evidence of intrahospital transmission. J Clin Microbiol 47:1920-1922.

Guglierame P, Pasca MR, De Rossi E, Buroni S, Arrigo P, Manina Gand Riccardi G (2006) Efflux pump genes of the resistance-nodulation-division family in Burkholderia cenocepacia genome. BMC Microbiol. 6:66.

Hernandez-Alles S, Alberti S, Alvarez D, Domenech-Sanchez A, Martinez-Martinez L, Gil J, Tomas JMand Benedi VJ (1999) Porin expression in clinical isolates of Klebsiella pneumoniae. Microbiology 145:673-679.

Huang YTand Hsueh PR (2008) Antimicrobial drug resistance in Taiwan. Int J Antimicrob Agents.32 Suppl 3:174-178.

Husain Fand Nikaido H (2010) Substrate path in the AcrB multidrug efflux pump of Escherichia coli. Mol Microbiol 78:320-330.

Jiang X, Espedido BA, Partridge SR, Thomas LC, Wang Fand Iredell JR (2009) Paradoxical effect of Klebsiella pneumoniae OmpK36 porin deficiency. Pathology 41:388-392.

Jiang Y, Yu D, Wei Z, Shen P, Zhou Zand Yu Y (2010) Complete nucleotide sequence of Klebsiella pneumoniae multidrug resistance plasmid pKP048, carrying blaKPC-2, blaDHA-1, qnrB4, and armA. Antimicrob Agents Chemother 54:39673969.

Kaczmarek FM, Dib-Hajj F, Shang Wand Gootz TD (2006) High-level carbapenem resistance in a Klebsiella pneumoniae clinical isolate is due to the combination of bla(ACT-1) beta-lactamase production, porin OmpK35/36 insertional inactivation, and down-regulation of the phosphate transport porin phoe. Antimicrob Agents Chemother 50:3396-3406.

Kontopoulou K, Protonotariou E, Vasilakos K, Kriti M, Koteli A, Antoniadou Eand Sofianou D (2010) Hospital outbreak caused by Klebsiella pneumoniae producing KPC-2 betalactamase resistant to colistin. J Hosp Infect 76:70-73.

Landman D, Bratu Sand Quale J (2009) Contribution of OmpK36 to carbapenem susceptibility in KPC-producing Klebsiella pneumoniae. J Med Microbiol 58:1303-1308.

Lee K, Yong D, Choi YS, Yum JH, Kim JM, Woodford N, Livermore DMand Chong Y (2007) Reduced imipenem susceptibility in Klebsiella pneumoniae clinical isolates with plasmid-mediated CMY-2 and DHA-1 beta-lactamases comediated by porin loss. Int J Antimicrob Agents 29:201206.

Maltezou HC, Giakkoupi P, Maragos A, Bolikas M, Raftopoulos V, Papahatzaki H, Vrouhos G, Liakou Vand Vatopoulos AC 
(2009) Outbreak of infections due to KPC-2-producing Klebsiella pneumoniae in a hospital in Crete (Greece). J Infect 58:213-219.

Martinez-Martinez L (2008) Extended-spectrum beta-lactamases and the permeability barrier. Clin Microbiol Infect.14 Suppl 1:82-89.

Munoz-Price LSand Quinn JP (2009) The spread of Klebsiella pneumoniae carbapenemases: a tale of strains, plasmids, and transposons. Clin Infect Dis 49:1739-1741.

Piddock LJ (2006) Clinically relevant chromosomally encoded multidrug resistance efflux pumps in bacteria. Clin Microbiol Rev 19:382-402.

Pournaras S, Kristo I, Vrioni G, Ikonomidis A, Poulou A, Petropoulou Dand Tsakris A (2010) Characteristics of meropenem heteroresistance in Klebsiella pneumoniae carbapenemase (KPC)-producing clinical isolates of $\mathrm{K}$. pneumoniae. J Clin Microbiol 48:2601-2604.

Shi WF, Jiang JP, Xu N, Huang ZMand Wang YY (2005) Inhibitory effects of reserpine and carbonyl cyanide m-chlorophenylhydrazone on fluoroquinolone resistance of Acinetobacter baumannii. Chin Med J 118:340-343.
Su LH, Chu C, Cloeckaert Aand Chiu CH (2008) An epidemic of plasmids? Dissemination of extended spectrum cephalosporinases among Salmonella and other Enterobacteriaceae. FEMS Immunology \& Medical Microbiology 52:155-168.

Wang XD, Cai JC, Zhou HW, Zhang Rand Chen GX (2009) Reduced susceptibility to carbapenems in Klebsiella pneumoniae clinical isolates associated with plasmid-mediated beta-lactamase production and OmpK36 porin deficiency. J Med Microbiol 58:1196-1202.

Yamada Y, Ishii Y, Kouyama Y, Katho M, Odashiro R, Yamahata K, Tateda K, Yamaguchi Kand Suwabe A (2009) Characterization of Klebsiella pneumoniae producing SHV-12 and DHA-1 beta-lactamases accompanied by carbapenem resistance during hospitalization in a chronic care ward in Japan. J Chemother 21:445-447.

Zhang Y, Bao Q, Gagnon LA, Huletsky A, Oliver A, Jin Sand Langaee T (2010) ampG gene of Pseudomonas aeruginosa and its role in beta-lactamase expression. Antimicrob Agents Chemother 54:4772-4779.

All the content of the journal, except where otherwise noted, is licensed under a Creative Commons License CC BY-NC. 